\title{
Impact of Long-Term Loading on Reinforced Concrete Beams Made with Partial Replacement of Coarse Aggregates with Recycled Aggregates from Old Concrete
}

\author{
Mahboob Oad \\ Department of Civil \\ Engineering, Quaid-e-Awam \\ University of Engineering, \\ Science \& Technology, \\ Nawabshah, Pakistan \\ engrmahboob04@gmail.com \\ Abdul Hafeez Buller \\ Department of Civil \\ Engineering, Quaid-e-Awam \\ University of Engineering, \\ Science \& Technology, \\ Nawabshah, Pakistan \\ engrabdulhafeezbuller@gmail.com
}

\author{
Bashir Ahmed Memon \\ Department of Civil \\ Engineering, Quaid-e-Awam \\ University of Engineering, \\ Science \& Technology, \\ Nawabshah, Pakistan \\ basher_m@hotmail.com
}

\author{
Noor Ahmed Memon \\ Department of Civil \\ Engineering, Quaid-e-Awam \\ University of Engineering, \\ Science \& Technology, \\ Nawabshah, Pakistan \\ nahmedmemon@gmail.com
}

\begin{abstract}
This research work presents an experimental evaluation of the effect of sustained loading on reinforced concrete beams made with $50 \%$ replacement of natural coarse aggregates with aggregates from old concrete. A total of 9 RC beams were cast, 6 with natural coarse aggregates and 3 with recycled concrete aggregates. All beams were cured for 28 days in standard fashion. Among the first batch, 3 beams were used to test under short term loading till failure. An application of $\mathbf{5 0 \%}$ of short-term loading followed on all beams assembled on purpose made frames. All beams were monitored for deflection, strain, and cracking. Both deflection and strain remained within limits. Crack monitoring revealed maximum crack width 0.5 mm. After six months of sustained load, beams were removed from the frames and tested in universal load testing machine with central point load till failure. The load-deflection pattern of all beams was observed to be almost similar and $22.12 \%$ higher in recycled concrete beams than all-natural aggregate beams. The results show promising use of recycled concrete aggregates in new concrete subjected to sustained loading.
\end{abstract}

Keywords-recycled concrete aggregates; green concrete; longterm loading; flexural strength

\section{INTRODUCTION}

Concrete is one of the most common and versatile materials used around the globe. Demolishing of old concrete structures generates huge amounts of waste. Dealing with this waste particularly in areas where dumping space is less or unavailable is a serious problem, and dumping this waste raises several environmental issues. One of the prominent aspects of dealing with this waste is by reusing it in new concrete leading to production of green concrete. Several components of the demolishing waste have been used in new concrete as replacements of fine and coarse aggregates. The bulk amount of demolishing waste is concrete and can effectively be used as coarse aggregates. Old concrete has been studied by several scholars as partial or full replacement of coarse aggregates in new concrete. In this regard, author in [1] presented a review on the recent developments about the use of recycled aggregates and summarized its use, limitations and the state-ofthe-art achieved in recent years.

Fresh and hardened properties of new concrete with coarse aggregates from old concrete under short term loading have also been studied, although the scatter in reported results shows that still a lot of work is required to be done in this field to improve the confidence in the use of this material. On the other hand, structures during service life are applied with sustained loading / long term loading. Creep, shrinkage and deflection due to long term loading are important parameters which generate and redefine the stresses in reinforced concrete members thus need to be studied to ensure proper design and thus proper functioning of the reinforced concrete members. In this regard, authors in [2] determined creep and shrinkage of concrete with recycled coarse aggregates. They used 0.5 and 0.65 water-cement ratio with $0 \%, 20 \%, 50 \%$ and $100 \%$ dosage of recycled aggregates to study the proposed parameters for 1000 days. They observed that both parameters increased with increased dosage of recycled aggregates. Also, different behavior was recorded due to the use of pre-saturated coarse aggregates. Finally, numerical expression was developed to predict shrinkage and creep coefficients at early age and internal curing effect. In [4], the same authors used the same parameters to study long-term deflection. Flexural capacity of reinforced concrete beams with recycled concrete aggregates has been studied in [7, 9]. Authors studied the combined effect of corroded steel and sustained loading on the flexural performance of reinforced concrete beams. Authors in [10] conducted experimental work to check the long-term behavior of FRC (polymer and glass fibers) flexural beams under

Corresponding author: M. Oad 
sustained load. In [11], authors used glass polymer bonded to tension face of reinforced concrete beams to check flexural behavior. Based on the outcome of their studies it is observed that recycled aggregate concrete is valuable as structural material. Deflection due to long term loading has been studied in [3] considering normal and high-strength concrete and by taking into compressive strength, compressive zone reinforcement and dimension of reinforced concrete beams. Authors in [5] also studied it by using Bayesian analysis as a more improved technique than probabilistic prediction. Authors in [14] used $0 \%, 30 \%$ and $100 \%$ replacement of natural coarse aggregates and $w / c$ ratios of $0.35,0.45$ and 0.6 and aggregate to cement ratios of 3, 4.5 and 6 to study the same. Authors in [15] checked long-term deformation in recycled aggregate concrete due to creep and shrinkage. Authors in [6] used recycled aggregates and high-volume fly ash to study long-term deflection, creep and shrinkage of reinforced concrete beams. Almost all above-mentioned studies reported increase in deformation due to the increase in dosage of recycled aggregates. Effects of long-term deformation on creep, shrinkage and other properties of concrete are also evident from the results. A comparison of the results shows that recycled concrete aggregates can be used in new concrete.

Refinement of relevant provisions of BS8110 and Eurocode 2 for tension stiffening decay with time were addressed in [12] and revisions for behavior modeling were proposed. A collective study of pore size distribution and mechanical properties was done in [13] with the use of recycled aggregates from different sources. Based on the test results of 5-year cured concrete samples, authors concluded that there is good correlation between porosity and strength of the concrete. Authors in [17] studied the long-term deflection and flexural behavior of $\mathrm{RC}$ beams with recycled aggregates under sustained loading for more than 1 year. They compared the experimental results and based on their observations they proposed a modified equation to predict the long-term deflection of reinforced concrete beams with recycled aggregates. The output of the proposed equation showed good agreement with the experimental results. Authors in [16] researched regarding the mortar attached to old concrete aggregates and introduced the residual-mortar-factor to existing ACI and CEB methods for calculating creep and drying shrinkage. They observed that with the proposed technique creep and drying shrinkage are lower compared to their conventional counterpart. Authors in [18] developed formulas to compute long-term deflection of cracked reinforced concrete beams. They assumed all important parameters along with stress in steel in accordance with experimental tensile stress in steel. The output of the proposed function was compared with 217 reinforced concrete beams from the literature under sustained loading and showed good agreement between the two sets.

From the above discussion of relevant literature, it is evident that more work is required in the field to develop the confidence in using recycled concrete aggregates. Therefore, this paper presents laboratory testing of reinforced concrete beams made with $50 \%$ replacement of natural coarse aggregates with recycled old concrete under 6-month loading. Specimen details, testing and results are given in relevant sections. Comparison of the results shows that concrete with recycled aggregates from old concrete performs well after 6 months of sustained loading.

\section{MODEL DESCRIPTION AND TESTING}

Large blocks of old demolished concrete were collected from a 40 year old demolished school. These large blocks were manually hammered to approximate size of $20 \mathrm{~mm}$ (Figure 1). After screening of the obtained material for debris, organic compounds, mortar pieces and cracked particles, sieve analysis was done in standard fashion to obtain well graded material. In parallel, sieve analysis of natural coarse aggregates was also done. The comparison of grading of both aggregates is given in Figure 2.

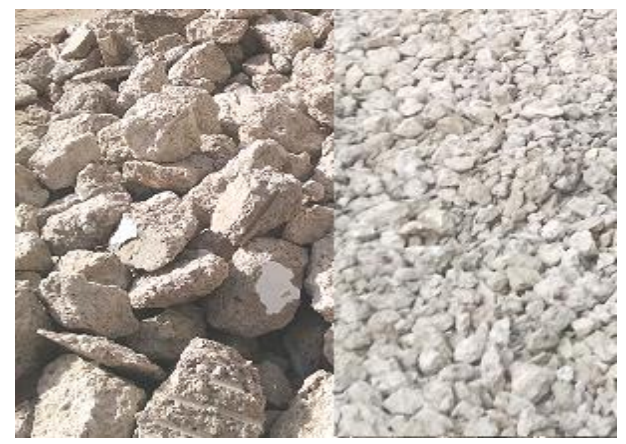

Fig. 1. Old concrete

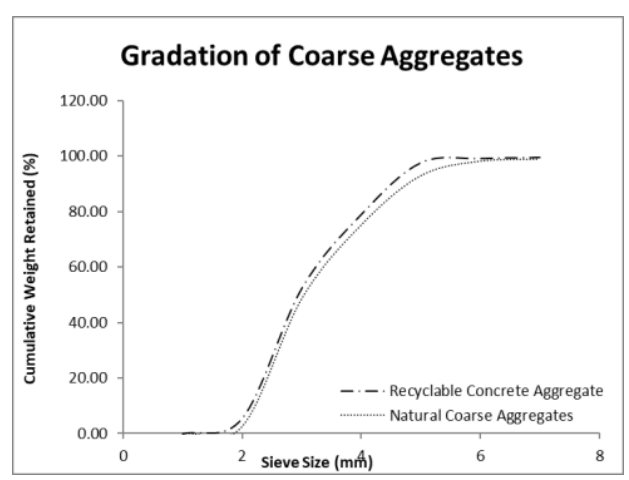

Fig. 2. Gradation of coarse aggregates

Using ordinary Portland cement, hill sand, natural coarse aggregates and coarse aggregates from old concrete, 3 reinforced concrete beams with $50 \%$ replacement of natural coarse aggregates were prepared. In addition, 6 reinforced concrete beams with all-natural coarse aggregates were also prepared and used as control specimens. For preparation of all the beams 1:2:4 mix was adopted. Water-cement ratio of 0.5 was used for the preparation of control specimens, whereas, water cement ratio of 0.6 was used to cast the proposed beams. Increased water-cement ratio was used to keep the same workability of concrete in both cases. For all beams, dimensions were kept the same and equal to $1875 \mathrm{~mm} \times 150 \mathrm{~mm} \times 300 \mathrm{~mm}$. $2 \# 4$ bars were used in both tension and compression zones with \#3 bars as stirrups at $150 \mathrm{~mm}$ center to center throughout the length of beam. After casting in standard manner, all the beams were cured in water for 28 
days. Reinforced concrete beams made up of all-natural aggregates are termed as NB1, NB2 and NB3. Whereas, notation of RB1, RB2 and RB3 is used for the beam cast with $50 \%$ recycled concrete aggregates. After the elapse of curing time, 3 beams made of all-natural aggregates were tested in universal load testing machine to determine the maximum load carrying capacity. The average of the 3 specimens was $74.022 \mathrm{kN}$. Pads were applied on the remaining reinforced concrete beams in center location with $25 \mathrm{~mm}$ center to center along the depth of beams for strain measurement. Then the beams were mounted on purpose made frames to test for long term loading (Figure 3) one-point load at center. Dial gauges were fixed at center location below the beams to measure deflection. $50 \%$ of the load obtained from short-term load testing was applied on each beam by means of screw jack and load cell system. Deflection, strain and cracking were monitored on a daily basis for all beams. Under sustained loading, deflection and strain values were measured on daily basis. The maximum values of deflection and average of all 11 readings of strain at the end of 6 months are given in Table I.

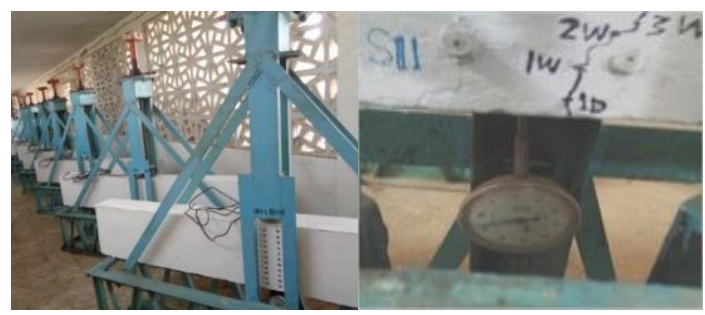

Fig. 3. Reinforced concrete beams for testing under long term loading.

TABLE I. DEFLECTION AND STRAIN AFTER 6 MONTHS LOADING

\begin{tabular}{|c|c|c|c|c|c|c|}
\hline Parameter & NB1 & NB2 & NB3 & RB1 & RB2 & RB3 \\
\hline Deflection $(\mathrm{mm})$ & 1.97 & 2.04 & 2.11 & 2.10 & 2.22 & 2.15 \\
\hline Strain $\left(\times 10^{-3}\right)$ & 2.31 & 2.36 & 2.38 & 2.43 & 2.45 & 2.41 \\
\hline
\end{tabular}

\section{RESULTS AND DISCUSSION}

All parameters discussed earlier were monitored on daily basis and analyzed. Weekly and final values of the parameters were recorded. The increasing trend of deflection and strain confirms the normal behavior of the beams. Maximum deflection among all 6 beams was recorded for RB2 and was equal to $2.22 \mathrm{~mm}$ at the end of the 6-month loading. The same beam also showed maximum strain equal to 0.00245 . Maximum deflection and strain values of all beams are shown in Figures 4 and 5. The values obtained are within the allowable limits of the parameters of ACI-318-95 provisions. During sustained loading, cracking in the beams was observed and marked and measured. Weekly marking of cracks in all beams is shown in Figure 7. Although Figure 7 shows a closed exaggerated view of the beams, yet it was observed and recorded that the maximum crack width was equal to $0.5 \mathrm{~mm}$, which confirms minor cracks under sustained loads thus better utilization of demolished aggregates form old concrete in new concrete.

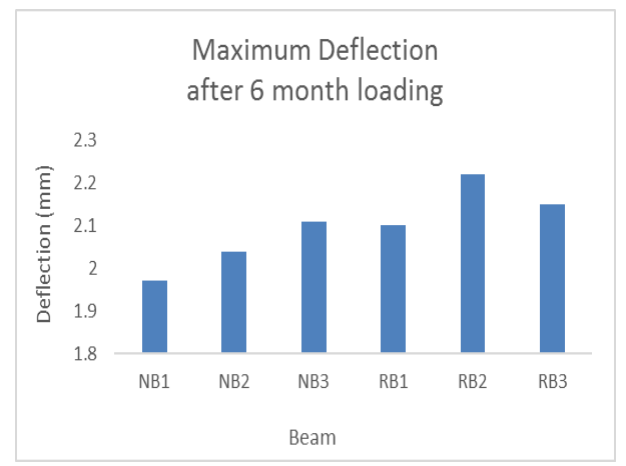

Fig. 4. Maximum deflection

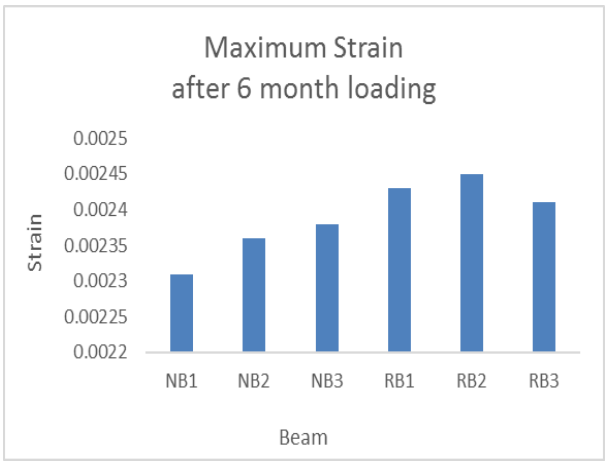

Fig. 5. Maximum strain

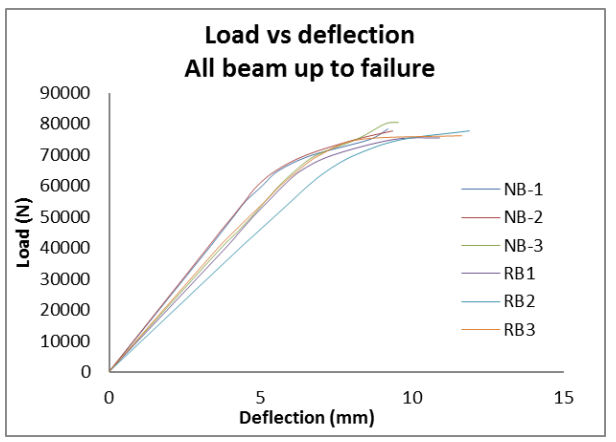

Fig. 6. Load vs deflection
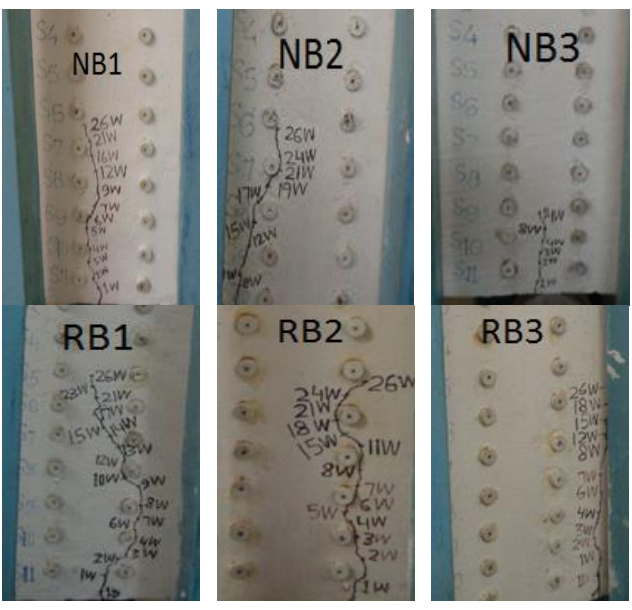

Fig. 7. Crack monitoring in beams under sustained loading 
After 6 months of sustained loading, load on the beams was removed and all the beams were tested under central point load till failure in a universal load testing machine. During the testing, deflection was recorded at regular intervals. The loaddeflection behavior of all beams is shown in Figure 6. It may be observed from this Figure that the pattern of deflection increase is the same in all beams, however the reinforced recycled concrete aggregate beams exhibited more deflection compared to reinforced natural aggregate beams. The maximum deflection observed in reinforced recycled aggregate beams is equal to $11.65 \mathrm{~mm}$ which is $22.12 \%$ higher than the maximum deflection observed in reinforced natural aggregate beams. Both recycled concrete aggregate and natural aggregate beams exhibited shear failure, showing proper functioning of the RCA beams under loading. Based on the above findings it is concluded that recycled concrete aggregates can comfortably be used in new concrete subjected to sustained loads up to six months.

\section{CONCLUSIONS}

Based on the findings of this research work, the following conclusions are made:

- Deflection and strain of reinforced concrete beams having partial replacement of natural aggregates with recycled concrete aggregate and all-natural aggregates are within allowable limits of ACI-318-95.

- Reinforced RCA beams exhibited higher deflection and strain than reinforced natural aggregate beams.

- During sustained loading cracks were monitored and crack width was evaluated. Maximum crack width recorded is $0.5 \mathrm{~mm}$.

- After 6 months of sustained loading, beam testing till failure shows almost similar deflection trends.

- At peak load values, shear failure in all beams is observed.

Therefore, it is concluded that coarse aggregates from old demolished concrete can be used in new concrete subjected to sustained loading without compromising its properties.

\section{REFERENCES}

[1] B. A. Memon, "Recent Development on Use of Demolished Concrete as Coarse Aggregates", International Journal of Emerging Technology and Innovative Engineering, Vol. 2, No. 1, pp. 1-11, 2016

[2] S. Seara-Paz, B. Gonzalez-Fonteboa, F. Martinez-Abella, I. GonzalezTaboada, "Time-Dependent Behavior of Structural Concrete made with Recycled Coarse Aggregates. Creep and shrinkage", Construction and Building Materials, Vol. 122, pp. 95-109, 2016

[3] H. M. Muthana, "Long-Term Deflections for Normal and High Strength Reinforced Concrete Beams", Journal of Babylon University/Engineering Scineces, Vol. 20, No. 1, 2012

[4] S. Seara-Paz, B. Gonzalez-Fonteboa, F. Martinez-Abella, D. CarroLopez, "Long-Term Performance of Reinforced Concrete Beams with Recycled Coarse Aggregates", Construction and Building Materials, Vol. 176, pp. 593-607 2018

[5] B. Han, T. Y. Xiang, H. B. Xie, "A Bayesian Inference Framework for Predicting the Long-Term Deflection of Concrete Structures Caused by Creep and Shrinkage", Engineering Structures, Vol. 142, pp. 46-55, 2017
[6] N. Tosic, S. Marinkovic, N. Pecic, I. Ignjatovic, J. Dragas, "Long-Term Behavior of Reinforced Beams made with Natural or RecycledAggregate Concrete and High-Volume Fly Ash Concrete", Construction and Building Materials, Vol. 176, pp. 344-358, 2018

[7] W. P. Zhang, H. F. Zhang, X. L. Gu, W. Liu, "Structural Behavior of Corroded Reinforced Concrete Beams Under Sustained Loading", Construction and Building Materials, Vol. 174, pp. 675-683, 2018

[8] A. R Mari, J. M. Bairan, N. Duarte, "Long-Term Deflections in Cracked Reinforced Concrete Flexural Members", Engineering Structures, Vol. 32, No. 3, pp. 829-842, 2010

[9] A. Lapako, R. Grygo, "Long-Term Deformations of Recycled Aggregate Concrete (RAC) Beams made of Recycled Aggregates", 10th International Conference on Modern Building Materials, Structures and Techniques, Vilnius Lithuania, May 19-21, 2010

[10] E. Vasanelli, F. Micelli, M. A. Aiello, G. Plizzari, "Long-Term Behavior of FRC Flexural Beams under Sustained Load", Engineering Structures, Vol. 56, pp. 1858-1867, 2013

[11] S. H. Kim, K. B. Han, K. S. Kim, S. K. Park, "Stress-Strain and Deflection Relationship of RC Beam Bonded with FRPs under Sustained Load", Composites Part B: Engineering, Vol. 40, No. 4, pp. 292-304, 2009

[12] A .W. Beeby, R. H. Scott, A. E. K. Jones, "Revised Code Provisions for Long-Term Deflection Calculations", Proceedings of the Institution of Civil Engineers, Structures \& Buildings, Vol. 158, No. 1, pp. 71-75, 2005

[13] S. C. Kou, C. S. Poon, M. Etxeberria, "Influence of Recycled Aggregates on Long-Term Mechanical Properties and Pore Size Distribution of Concrete", Cement and Concrete Composites, Vol. 33, No. 2, pp. 286-291, 2011

[14] V. W. Y. Tam, D. Kotrayothar, J. Xiao, "Long-Term Deformation Behaviour of Recycled Aggregate Concrete", Construction and Building Materials, Vol. 100, pp. 262-272, 2015

[15] A. Domingo, C. Lazaro, F. L. Gayarre, M. A. Serrano, C. Lopez-Colina, "Long-Term Deformations by Creep and Shrinkage in RecycledAggregate Concrete", Materials and Structures, Vol. 43, No. 8, pp. 1147-1160, 2010

[16] G. Fathifazl, A. G. Razaqpur, O. B. Isgor, A. Abbas, B. Fournier, S. Foo, "Creep and Drying Shrinkage Characteristics of Concrete Producedwith Coarse Recycled Concrete Aggregate", Cement and Concrete Composites, Vol. 33, No. 10, pp. 1026-1037, 2011

[17] W. C. Choi, H. D. Yun, "Long-Term Deflection and Flexural Behavior of Reinforced Concrete Beams with Recycled Aggregates", Materials \& Design, Vol. 51, pp. 742-750, 2013 